\title{
$\checkmark$ \\ Subjetividade e tecnologia: a comunicação de longe e de perto
}

\author{
Márcio Acserald \\ Universidade Federal do Rio de Janeiro
}

Depois que a tecnologia inventou telefone. telégrafo, televisão, todos os meios de comunicação a longa distância é que se descobriu que o problema da conmunicação era o de perto. Millör Fernandes

Pode parecer incrivel a nossos ouvidos tão impregnados de mensagens, mas houve uma época em que era preciso muita luta para se vencer o silêncio e a distância e assim estabelecer a comunicação. Tempo de mares bravios, de guerras tribais e monstros invisíveis. Tempo de terras estranhas, de brumas e de aventuras. Tempo de mistério e decifração. Tudo isto muda radicalmente com o advento do mundo moderno, em que a comunicação vai desempenhar progressivamente um papel mais importante até que "não haja uma única molécula de ar que não vibre com as ondas de rádio, nem um metro quadrado deste globo que escape à vigilância dos satélites ou sonares"'.

Nosso mundo vem se caracterizando mais e mais pela influência dos diversos meios de comunicação a distância sobre a produção de subjetividade. O papel desempenhado pelo jornal no final do século $\mathrm{XIX}$, pelo rádio e pela televisão na primeira metade deste século e pelo computador e pelas redes informáticas nesta segunda produziram e produzem, cada qual a seu tempo, mudanças profundas na forma como o homem pensa, fala e age. Os diversos mídia terminaram por realizar uma revolução sem precedentes na história da humanidade, unindo o tempo e o espaço num presente hipercontraído e fazendo com que o planeta pudesse ser pensado como uma grande aldeia global. As novas tecnologias já são parte integrante de nossas vidas e fazse necessário pensar as conseqüências decorrentes desta mistura de subjetividade e objetividade, de homem e máquina, de natureza e cultura que Bruno Latour houve por bem denominar 'hibridação'2 . É o que vem realizando, por exemplo, uma equipe de pesquisa do departa- 
mento de Psicologia da PUC-RJ, sob a coordenação da professora Ana Maria Nicolaci-da-Costa, que deu início à pesquisa movida pelo espanto de se encontrar frente a uma máquina diferente de todas as que já havia conhecido. Ela narra sua primeira experiência nas 'maIhas da rede': "Sem me dar conta do que estava acontecendo, esqueci o dia, esqueci o lugar onde estava, esqueci mesmo que estava na frente de uma tela, e minha aluna e eu ficamos lá quatro horas seguidas! $E$ eu acho que viajei mais nessas quatro horas do que durante todos os meus anos de vida. E em nenhuma viagem que eu tenha feito, ou possa vir a fazer, eu poderia ter ido, ou poderei ir, a tantos lugares em tão pouco tempo"3.

Várias foram as correntes de pensamento preocupadas com as conseqüências produzidas por estas mudanças na sociedade como um todo, nos indivíduos e nas interrelações entre indivíduos e sociedade. Dentre estas destacamos, por seu caráter inaugural, a escola que se estabeleceu em Frankfurt em meados da década de 1920 e que desenvolveu um pensamento crítico quanto à maneira de se pensar a ciência, a tecnologia e os meios de comunicação em sua influência nos níveis macro (social) e micro (individual). Depois de Frankfurt, não era mais possível se pensar a cultura apenas como algo positivo e o progresso científico como desvinculado de uma ideologia. "No colapso atual da civilização burguesa o que se torna problemático é não apenas a atividade mas o sentido da ciência"4. A idéia de verdade nunca mais foi a mesma. Também a idéia de subjetividade sofreu uma revisão importante, principalmente com o advento do conceito de massa, o correspondente subjetivo das transformações tecnológicas ocorridas na esfera da cultura e da comunicação. "As massas foram educadas tecnologicamente para deixar dominar-se pelo fascínio de um despotismo qualquer"' , afirmam Adorno e Horkheimer. A uma visão utópica da tecnologia os pensadores de Frankfurt contrapõem um ponto de vista radicalmente crítico, chamando a atenção para o movimento globalizador que se iniciava e para a tendência conservadora ali presente. $O$ pensamento crítico via no crescente domínio planetário do poderio da indústria cultural uma forma de a sociedade contemporânea "não mais ir além de si própria em suas formas de consciência mas sim de reforçar tenazmente o status quo e, sempre que ele pareça ameaçado, reconstruí-lo" . Mauro Wolf resume: "Para a teoria crítica, trata-se de instrumentos de reprodução de massa que, na liberdade aparente dos indivíduos, reproduzem as relações de força do aparelho econômico e social"' 
Mas seriam tais visões (tanto a utópica, que via na técnica uma possivel solução para todos os males que nos afligem, quanto a críti$\mathrm{ca}$, temerosa de que na realidade nos aproximamos de uma barbárie sem precedentes) ainda válidas para se pensar a relação que se estabelece hoje entre tecnologia e subjetividade? Será que conceitos como indústria cultural e cultura de massa ainda são capazes de nos incitar a pensar criticamente as mudanças ocorridas no mundo nesta segunda metade do século $X X$ ?

A idéia central deste trabalho é refletir sobre o que muda na subjetividade com o desenvolvimento dos meios de produção midiática e com o caminho percorrido pelo capitalismo pós-industrial. Seriam as soluções apontadas por autores como Habermas, Adorno e Horkheimer ainda válidas? Ainda há lugar no mundo para uma retomada da racionalidade em bases comunicacionais, ou estaremos fadados ao destino apontado pelo pensamento pós-moderno, em que todos os discursos se equivalem em sua idêntica falta de meta-referências confiáveis? Que papel desempenham aí as novas tecnologias como as redes transnacionais de computação? O que muda na relação estabelecida entre a televisão e seu público, entre o homem e a informação?

A tecnologia, que já não pode ser ignorada caso desejemos pensar o mundo em que vivemos e as alterações ocorridas nos últimos anos, costuma ser pensada de duas formas diferentes por autores oriundos das mais diversas áreas de pesquisa. Por alguns ela é vista como uma substância diabólica, algo que se apossa de nós e sobre o que não temos o menor controle. Por outros é vista como a redenção final, a última pedida em termos de democratização de conhecimentos e interação humana. Como qualquer outro rótulo, estes tratam de forma única o que em realidade representa um conjunto de fenômenos dispares e por vezes mesmo contraditórios. Pensar a tecnologia hoje implica em pensá-la como fenômeno complexo e qualquer tentativa de simplificação que se proponha a prever os resultados de uma tão recente transformação resultará maléfica para a compreensão da mesma. É preciso que nos livremos de um certo terrorismo filosófico que, principalmente nos anos que se seguiram à Segunda Grande Guerra, trataram de denegrir toda e qualquer tecnologia apontando ai para os maleficios causados, por exemplo, pelo desenvolvimento de armamentos capazes de destruir várias vezes a totalidade do planeta. No terreno das comunicações, o temor diante da tecnologia se mostrava pelo modelo de irradiação altamente centralizado presente principal- 
mente no uso da televisão a partir da década de 1960, em que o público atendia pelo nome de 'massa'. Aqui o receio era não tanto a destruição física de nosso mundo mas antes a destruição intelectual, o retorno à barbárie da indiferenciação, à ignorância e à passividade face a um poder tecno-burocrático altamente centralizado.

É igualmente necessário evitar generalizações utópicas e demasiado acríticas como as que se apresentam no trabalho de George Gilder, que vê na tecnologia a solução para todos os males, desde as desigualdades sociais até as falhas de comunicação: "The nascent telecosm will empower individuals and families in work, education, entertainment, medicine and even politics"8. É importante, no entanto, perceber a importância do pensamento de Gilder e de outros autores, como Simon Nora e Alain Minc ${ }^{9}$, preocupados com a influência do estado no controle do cyber-espaço. Com uma proposta de desregulamentação radical, Gilder aposta que o papel do estado em assuntos desta ordem deve ser apenas um: retirar-se para que então se possa desenvolver uma verdadeira ágora informacional. "The best solution is a freedom model of de-regulation which would allow all existing and future companies to interact in each others' business markets without undue government interference or delay"10. Este modelo que, na aparência apresenta-se como a mais avançada forma de liberdade de comunicação não deixa transparecer o cunho ideológico que carrega. Nem todos (os países e os indivíduos) estão preparados para esta mudança que se avizinha. A desregulamentação pura e simples, estratégia neoliberal que avança dia a dia, esconde um fato crucial: a grande maioria das mensagens (leia-se, dos produtos) veiculadas no cyber-espaço provém dos Estados Unidos que, uma vez desregulamentada a rede, passariam a gerir a economia mundial com mais facilidade do que nunca.

Otimistas e pessimistas tendem a concordar em uma coisa: o desenvolvimento dos meios de comunicação à distância é um fato histórico de importância ímpar. Queiramos ou não, a tecnologia está viva e cada vez mais presente em nosso cotidiano. Mas não se pode esperar que uma técnica resolva problemas não técnicos, alerta Daniel Bougnoux:

"Ficamos esperando que as técnicas produzam uma cultura. ... Em geral a técnica não é bem recebida, acusada de falsear uma intimidade sonhada, o cara a cara 'original' do homem com a natureza, com seu semelhante ou consigo mesmo. $O$ fato de termos necessidade, por exemplo, de utensílios para pensar é uma afronta à nossa completude 
imaginária. Em que domínios a techné poderia substituir a physis? Não sabemos fabricar nem reparar tecnicamente o que a técnica destruiu (ozônio, baleias e borboletas, para não dizer nada das culturas humanas em vias de extinção). O século XIX, que descobriu a história e também o maquinismo industrial estendeu este prometeísmo triunfante à fabricação do social através de projetos de revolução radical. O fim do século $X X$ está em vias de redescobrir na natureza e na complexidade do social o que resiste ao desenvolvimento prometéico e à sua extrapolação linear. Em que medida estas técnicas que fragmentam o mundo poderão, juntando-se às técnicas da comunicação, remediar as taras do modo de produção técnica em geral? O paradoxo ou ilusão constitutiva da 'comunicação' é que, produzida tecnicamente, ela pretende não somente escapar ao mundo técnico mas corrigir seus excessos" "I.

Como se vê, não é possível esperar-se uma solução técnica para o problema. Embora colocado por inovações tecnológicas, é na ética que se deve buscar as ferramentas para lidar com as inusitadas modificações instauradas pela era da comunicação midiática.

A questão que se coloca então é a seguinte: as caracteristicas da mídia (entendida aqui como o conjunto de dispositivos informáticos e telepáticos) the são inerentes, integrando mesmo seu modo de ser; ou são contingências adquiridas pelo modo histórico pelo qual ela surgiu no bojo do capitalismo? Em outras palavras, é possivel se pensar uma era pós-mídia, ou as massas já estariam definitiva e irremediavelmente condicionadas a não pensar? Existe ética para a mídia ou ela está fadada a não ser mais que 'ilusão de ética'?

Para Louis Porcher, aulor do pequeno cnsaio Vers la dictature des média?'? não é a mídia que se erige em ditadora, mas sim aqueles que a controlam. Basta se estar atento e saber retirar suas máscaras. Em outras palavras, seria suficiente uma socialização dos aparatos técnicos midiáticos, como citados pelo autor nas experiências de televisões comunitárias de Quebec e Montreal. Felix Guattari concorda que a questão passe pelo desmascarar, pela socialização dos meios de produção, mas que também se fazem necessários novos modos de enunciação, fundados numa ética da finitude: "A passagem da era consensual midiática a uma era dissensual pós-midiática permitirá a cada um assumir plenamente suas potencialidades processuais e fazer, talvez, com que esse planeta, hoje vivido como um inferno por quatro quintos de sua população, transforme-se num universo de encantamentos criadores"'.3. Para tal seria necessessário um processo pelo 
qual os indivíduos se reapropriariam dos componentes de subjetivação, ao qual ele dá o nome de singularização, e que não se restringe à reapropriação dos meios de produção ou de expressão, mas passa pelo campo da "economia subjetiva", uma economia a um tempo política e desejante.

Daniel Bougnoux nos apresenta um interessante modelo para se pensar a comunicação. Segundo o autor, comunicação é antes de mais nada luta, luta por dizer algo em meio a um mar revolto de enunciados em perpétuo conflito. Para que um fale é preciso que outros se calem e escutem. Toda comunicação é polêmica, deve abrir, à força ou com astúcia, seu caminho em um meio já saturado de mensagens. Do casal às nações, as manipulações simbólicas estão a serviço dos jogos de legitimação e de poderes. Um discurso é antes de tudo um percurso, e como tal é semeado de emboscadas e armadilhas. A inscrição de um traço supõe a rasura de outros e os enunciados vencedores são os que reforçam ou racionalizam as crenças dos respectivos portadores, que levam a ganhar posições no front comunicacional, que permitem a economia de enunciados. Ruído, assim, não é uma simples interferência externa que altere a eficácia na transmissão de uma mensagem: ruído é a informação dos outros, aquela contra as quais se deve lutar. Assim como não há ruído puro, também não há informação pura, universal, válida ou interessante para todos. Informação é pensada como tudo o que enriquece o equipamento cognitivo de cada um em determinado instante, variando segundo os indivíduos e também conforme as circunstâncias. Este caráter temporal da informação faz com que ela não seja vista como um absoluto ou um universal, mas que se a perceba como singular e mutável. "Nada é mais relativo e se torna caduco mais depressa do que uma informação"/4.

O modelo que se costuma utilizar para pensar os meios de comunicação em sua relação com as massas é o da irradiação. Guillaume caracteriza este modelo como constando de dois pólos: um pólo central, que funciona lançando continuamente efeitos de mensagens sobre um outro polo difuso, descentralizado e desorganizado, que capta e decodifica as mensagens. O pólo receptor também responde pelo nome de massa. Como características principais da massa temos que "seus participantes são originários de quaisquer profissões e de qualquer categoria social. A massa é um grupo anônimo, ou melhor, é composta por indivíduos anônimos que interagem muito pouco entre si"'s. A este modelo opõe Guillaume um outro denominado de encadeamento, em que a circulação das mensagens não se dá mais a partir 
de um centro todo-poderoso, monopolizador da técnica de difusão e único dono do arsenal tecnológico necessário para a produção e propagação das mensagens. No encadeamento todos os membros da comunidade são a um tempo emissores e receptores e as mensagens circulam de modo seqüencial (e não mais simultâneo), retroagindo umas sobre as outras. "A epidemia, o rumor, a imitação, a circulação da violência pertencem a este segundo modelo. As vacinas, os meios de comunicação de massa, o controle social panóptico, a dissuasão militar (a Terra inteira irradiada pela ameaça nuclear) dependem do primeiro"16.

Assim é que para se pensar a comunicação na atualidade iremos adotar o modelo criado por Gregory Bateson, que leva em conta não somente os lados semântico e sintático da comunicação mas que considera antes de mais nada a comunicação como questão pragmática e portanto não-linear. Bateson prefere pensar o ato comunicativo como a entrada de um instrumento musical em uma orquestra e não como o envio telegráfico de determinada mensagem que parte de um emissor e chega até um receptor. $O$ modelo da orquestra explicita o fato de a comunicação ser um ato complexo e não-linear e que comunicar é pôr algo em comum, trazer algo que acrescente, que ajude a produzir diferença. Comunicar não é transmitir o que se sabe para alguém que não sabe, como se pensa nas instituições pedagógicas de inspiração platônica, mas antes é entrar em um jogo de regras permanentemente reconstruídas. Ao modelo da orquestra de Bateson podemos acrescentar um tempero chamado improviso: comunicar não é somente entrar na orquestra na hora certa, no momento exato previsto pela partitura e regido pelo maestro. É também improvisar, à maneira do jazz ou da roda de samba, é acrescentar algo de inovador, de imprevisivel, algo que não estava escrito. Comunicar, portanto, envolve em parte o conhecimento de um código mas supera em muito este conhecimento. É um ato complexo que implica uma boa dose de indeterminação, acaso e improviso.

Ora, a questão colocada pelas novas tecnologias de rede seria então a seguinte: estaríamos aos poucos deixando de ser regidos pelo modelo da irradiação, autoritário, pesado e centralizador, em nome da retomada do modelo baseado no encadeamento, mais leve e flexível, de forma semelhante àquela em vigor nas sociedades pré-industriais, portanto pré-midiáticas (donde a pertinência do termo 'aldeia' global)? Agora, no entanto, uma série de novidades se fazem presentes de modo que esta nova 'aldeia' tem características muito próprias, 
como por exemplo o fato de não se situar mais no espaço-tempo tradicionais. $\mathrm{O}$ espaço se des-espacializa enquanto o tempo torna-se instantâneo. Quanto ao sujeito, este também se des-subjetiviza: não é mais o personagem cartesiano, rígido e idêntico a si mas um sujeito nômade, sujeito em ação e da ação, que se constrói e reconstrói a todo instante à medida que age e reage às informações a que tem acesso:

O desenvolvimento dos novos instrumentos de comunicação se inscrevem em uma mutação de grande amplitude. Para dizer em uma palavra: voltamos a ser nômades. As imagens do movimento nos reenviam às 'viagens imóveis', fechados sobre um mesmo mundo de significações. Mover-se não é mais se deslocar de um ponto a outro mas atravessar universos de problemas, de mundos vividos, de paisagens de sentido. Somos imigrantes da subjetividade"17.

Uma das palavras-chave para se pensar as mudanças de paradigma da atualidade parece ser 'flexibilidade'. Seja em políticas administrativas, em teoria do conhecimento ou no gerenciamento de megacorporações, a flexibilidade torna-se um conceito-chave para

110 compreendermos as novas subjetividades que se constróem e desconstróem com rapidez. O tempo da especialização começa a ceder sua vez ao da capacidade de se mover em diversos espaços, de se adaptar às velozes mudanças ocorridas no mundo em face dos avanços tecnológicos. Nosso tempo, que já foi o da espera pela colheita; depois da ação pelo vapor, agora apresenta-se como da informação que viaja nas ondas da internet. É importante lembrar, no entanto, que uma tecnologia não substitui a outra: elas se acumulam, tornando a rede um intrincado e complexo mar de camadas superpostas. Gilberto Gil nos alerta para os paradoxos da tecnologia quando aproxima uma antena parabólica a um cesto de palha ou quando navega no infomar: "Criar meu web site/Fazer minha home-page/Com quantos gigabytes/ Se faz uma jangada/Um barco que veleje/Que veleje nesse infomar/ Que aproveite a vazante da infomaré"18.

E no entanto a própria flexibilização não pode ser erigida pura e simplesmente à condição de um novo paradigma simplista. Ela também apresenta-se complexa e paradoxal. Um dos paradoxos aqui presentes, aponta Armstrong seguindo o pensamento de Gregory Bateson, é que "tentativas simplistas de aumentar a flexibilidade podem resultar em uma maior rigidez"19. Como se vê, o problema está longe de encontrar uma única solução, já que experimentamos uma revolução em tempo real. Para tal um de nossos aliados deve ser o 
próprio conceito de paradoxo, que recentemente foi convidado a participar do aparato conceitual do ocidente uma vez que a lógica simplista e simplificadora do racionalismo se mostrou insuficiente para dar conta dos fenômenos complexos surgidos com as novas tecnologias e também com as mutações na própria concepção do homem e da vida ${ }^{20}$.

Vemos então que pesquisar os meios de comunicação deve implicar ao mesmo tempo em pesquisar a própria comunicação e sua vertente paradoxal, ao mesmo tempo técnica e humana, lógica e absurda. Pois comunicar não é apenas transmitir informações mas muito antes é transmitir-se a si próprio, o que levanta questões relativas à verdade e à subjetividade. Dai a inadequação apontada por Mauro Wolf: "A pesquisa sobre os meios de comunicação de massa parece fortemente inadequada porque se limita a estudar as condições presentes, acabando por se inclinar para o monopólio da indústria cultural"21. Daniel Bougnoux também chama a atenção para o caráter complexo da comunicação que, sendo em princípio uma produção técnica da cultura, vai muito além de uma simples técnica visto trazer em si boa dose de descontrole e imprevisibilidade"2.

A questão se torna ainda mais complexa se pensarmos em um mundo globalizado e no papel que nele cabe aos paises do chamado Terceiro Mundo [o fato de haver ainda um 'terceiro mundo' ainda que na ausência de um segundo deixa claro que a globalização não é nem pretende ser equânime, mas que o fosso entre ricos e pobres (paises e homens) só faz aumentar]. Assim como com as demais revoluções pelas quais o mundo passou, como a burguesa e a industrial, na revolução informática continuamos habitando a periferia do capitalismo, e as consequiências de tal posição estão longe de serem despreziveis. Já que se trata da hora da virada, de um momento crucial na história do sujeito ocidental, vários caminhos se apresentam diante de nós, e devemos estar tão preparados quanto possivel para as tomadas de decisão que estão por vir. Mais do que nunca. é preciso se preparar para o imprevisivel, esperar o inesperado, abrir-se para o paradoxo. O momento é ambiguo uma vez que "as massas excluídas da história podem ser libertadas pela informação ou ser definitivamente sepultadas"2: Se antes a exclusão se dava nos moldes da posse de um código que dividiu o mundo entre alfabetizados e analfabetos, hoje surge um novo analfabetismo, que podemos chamar analfabetismo tecnológico: já não basta saber ler e escrever. É preciso saber manejar máquinas, fazer circular informações. agenciar-se a uma memória coletiva. 
"Quem antes era dominado porque desconhecia, pode continuar dominado porque incapaz de escolher entre tanta informação que the chega"24.

A realidade imposta pela nova 'aldeia global' da informática e telemática totais cria e manipula a ilusão de pertencimento e participação principalmente através da esfera do gozo e da fruição. Tal participação, no entanto, mostra-se reduzida tão somente à esfera do consumo, nunca chegando a atingir a esfera da produção. $O$ descentramento generalizado que se vê através dos processos de desregulamentação e desestatização abrem cada vez mais as portas para um capitalismo descontrolado e retro-alimentado. Que acontece então com a política? "Para alçar-se a uma extensão planetária, a política teve de esvaziar-se ao máximo. E neste vazio a ciência e a tecnologia vão substituindo a antiga arte política pelos poderes da informatização"2s.

$\mathrm{Na}$ era do individualismo utilitário burguês, era de imagens e simulação, o sujeito é visto mais do que nunca como um produto. Produto do meio, da história, do acaso. Produto do capital, do desejo do outro, da mídia. Um produto capaz de se auto-reproduzir e expandir, autopoiético por excelência, um advertisement perpétuo de si mesmo, alguém que tem sempre e a todo instante que vender uma imagem: a de alguém que sabe (o que quer), que pode, que consegue. A comunicação então passa a se dar como a troca de simulacros e o paradigma da verdade, tão caro a eras anteriores, é substituído pelo paradigma da eficácia, dos resultados práticos obtidos.

É neste tipo de mundo que a mídia é erigida à condição de fim em si mesmo. Mas a mídia, o próprio nome o diz, só pode ser meio, nunca fim. Só quando desaparecem os critérios, os referenciais metafisicos de toda ordem, pode surgir uma cultura referenciada apenas pelos meio, pelo entre, pelo através. Passa a importar pouco o que está se passando, o como sendo de muito mais interesse. Mais efeitos, menos conteúdos. Pesquisas mostram que quando se assiste televisão na companhia de outros membros da familia, independente do tipo de programação, as pessoas relatam que se sentem menos nervosas, menos desafiadas, menos ativas e mais descontraídas. No dizer de Muniz Sodré, "Não se vê nada na tv. Se vê $\mathrm{tv}^{\prime 226}$. É ai, neste 'entre' que penetra o capitalismo, recheando, dando sentido a um meio vazio, isento de opinião e responsabilidade. No capitalismo, como na mídia, o recheio é o que menos importa. Aqui mais do que em qualquer outro sistema, o meio é a mensagem. Uma mensagem-massagem, como no trocadilho de McLuhan.

O fato é que generalizações de todas as ordens, tanto as demasiado 
pessimistas quanto as totalmente desvinculadas de qualquer postura crítica, não funcionam na complexa sociedade dos anos 90 como funcionavam em eras anteriores. Já não se pode mais pensar numa indústria cultural tão centralizada quanto a que se apresentava aos autores de Frankfurt. Hoje os casos têm de ser analisados um a um, sem anátemas, reprovações ou idéias preconcebidas. A tecnologia assume então sua feição paradoxal: nem redentora nem bandida, nem boa nem má: complexa, indeterminada e produtora de indeterminação.

Uma máquina em particular deve receber especial atenção devido às alterações imprevistas que causou e ainda deverá causar nas relações intersubjetivas. Tendo surgido inicialmente como um aparato calculador, o computador hoje altera radicalmente nosso modo de pensar questões como espaço, tempo. sujeito, inteligência, verdade, simulação. Muito mais do que uma ferramenta para calcular e prever, o computador passa a ser ao mesmo tempo um meio de transmissão de informações à distância prático, eficaz e barato; um mecanismo de pesquisa tornado indispensável e um parceiro do homem em seu imprevisivel e criador passeio pelo universo. Neste sentido ele é muito mais que um mídia, um meio de comunicação. Ele também é um interlocutor ativo no processo comunicacional, colocando mais uma vez em questão uma possivel divisão binária entrc o que é do campo do humano e o que dele está excluido.

Sem perdermos a consciência crítica diante do fenômeno tecnológico, hoje já é possível afirmar que certas inovações, principalmente no terreno das telecomunicações, podem vir a constituir fatores de democracia e bem-estar social, uma vez que acompanhados das respectivas mudanças no campo ético-político. Uma das características das inovações midiáticas dos últimos anos está no crescente aumento de autonomia por parte dos usuários de aparelhos técnicos, principalmentc. com o surgimento da noção de rede. Mais do que meros objetos assujeitados dos mídia, tal como se pensava segundo a teoria da indústria cultural, hoje passamos aos poucos à condição de novos sujeitos. Aumenta a capacidade de escolhas e principalmente a participação segundo o modelo de encadeamento, em que não há apenas um centro irradiador e monopolizador das informações mas múltiplos centros, e portanto centro nenhum. Hoje, mais do que meros telespectadores, começamos lentamente a passar à condição de teleatores. Para que este processo se propague, no entanto, faz-se necessário pensar a democratização do acesso às novas tecnologias, sem o qual caminharemos para um novo analfabetismo em níveis inimagináveis. 


\section{Bibliografia}

ACSELRAD, M. Os sentidos da verdade: multiplicidade, paradoxo $e$ linguagem Dissertação de Mestrado em Comunicação e Cultura, ECO/UFRJ, 1997.

ADORNO, T. "Televisão, consciência e indústria cultural" in COHN, G. (org.) Comunicação e indústria cultural. São Paulo: Companhia Editora Nacional.

ADORNO, T. W. \& HORKHEIMER, M. Dialética do Esclarecimento. Rio de Janeiro: Zahar, 1985.

ARMSTRONG, S. Migration as a metaphor for change with respect to legacy systems Computing Department, Faculty of Mathematics and Computing, Open University, Walton Hall.

BLUMER, H. "A massa, o público e a opinião pública" in COHN, G. (org.) Comunicação e indústria cultural. São Paulo: Companhia Editora Nacional.

BOUGNOUX, D., Introdução às ciências da informação e da comunicação. Petrópolis: Vozes, 1994.

CARNEIRO LEÃO, E. "Os desafios da informatização" in Aprendendo a pensar volume II. Petrópolis: Vozes, 1992.

GILDER, G. The freedom model of telecommunications. Artigo veiculado na Internet, adaptação da palestra realizada pelo autor no Senado americano em 2 de março de 1995.

GUATTARI, F. "Da produção de subjetividade" in Imagem-máquina: $a$ era das tecnologias do virtual. PARENTE, A. (org.) Rio de Janeiro: 34 Letras, 1993.

LATOUR, B. Jamais fomos modernos. Ed. 34, 1994.

LEVY, P. L'intelligence collective: pour une anthropologie du cyberspace. Paris: Découverte, 1994.

NASCIMENTO, A. E. e BARBOSA, J. P. Trabalho: história e tendências. São Paulo: Ática, 1996.

NICOLACCI-DA-COSTA, Ana Maria "A subjetividade nas malhas das redes" setembro de 1995, http://www.puc-rio.br/depto/psicologia/pesquisa/redes.htm.

MATTELART, A. e MATTELART, M. Histoire des théories de la communication. Paris: Éditions la découverte, 1995.

PORCHER, L. Vers la dictature des média? Paris: Hatier, 1976. 
SODRÉ, M. O social irradiado: violência urbana, neogrotesco e midia. São Paulo: Cortez, 1992.

SODRÉ, M. O monopólio da fala. Petrópolis: Vozes, 1985.

WOLF, M. Teorias da comunicação. Lisboa: Editorial Presença, 1985.

\section{Notas}

1 Bougnoux, D., Introdução às ciências da informação e da comunicação. Petrópolis: Vozes, 1994, p. 23

2 Segundo o autor, esta caracteristica hibrida sempre esteve presente, embora apenas agora possa ser pensada em toda a sua radicalidade. Nossa sociedade nunca funcionou plenamente de acordo com a premissa moderna da separação entre natureza e cultura. "Quanto mais nos proibimos de pensar os híbridos, mais seu cruzamento se torna possivel: este é o paradoxo dos modernos que a situação excepcional em que nos encontramos nos permite enfim captar." Latour, B. Jamais fomos modernos. Ed. 34, 1994, p. 17.

3 Nicolaci-da-Costa, Ana Maria "A subjetividade nas malhas das redes", artigo escrito em setembro de 1995 como parte do projeto de pesquisa "A internet e os brasileiros", do departamento de Psicologia da PUC-RJ. Cf. a homepage. http://www.puc-rio.br/depto/psicologia/pesquisa/redes.htm

4 Adorno, T. W. \& Horkheimer, M. Dialética do Esclarecimento. Rio de Janeiro: Zahar, 1985, p. 11.

5 idem, p. 13.

6 Adorno, T. "Televisão, consciência e indústria cultural" in Cohn, G. (org.) Comunicação e indústria cultural. São Paulo: Companhia Editora Nacional, p. 347.

7 Wolf, M. Teorias da comunicação. Lisboa: Editorial Presença, 1985, p. 84.

8 Gilder, G. The freedom model of telecommunications. Artigo veiculado na Internet, adaptação da palestra realizada pelo autor no Senado americano em 2 de março de 1995.

9 Cf. Nora, S. \& Minc, A. L'informatisation de la societé, 1978, citado por Mattelart, A. \& M. Histoire des théories de la communication. Paris: Éditions la découverte, 1995.

10 idem.

11 Bougnoux, D., Introdução às ciências da informação e da comunicação. Petrópolis: Vozes, 1994, p. 46. 
12 Porcher, L. Vers la dictature des média? Paris: Hatier, 1976.

13 Guattari, F. "Da produção de subjetividade" in Imagem-máquina: a era das tecnologias do virtual. Org. Parente, A. Rio de Janeiro: 34 Letras, 1993, p. 188.

14 Bougnoux, D., Introdução às ciências da informação e da comunicação. Petrópolis: Vozes, 1994, p. 25.

15 Blumer, H. "A massa, o público e a opinião pública" in Cohn, G. (org.) Comunicação e indústria cultural. São Paulo: Companhia Editora Nacional, p. 177.

16 Guillaume, M. La contagion des passions - essai sur l'éxotisme intérieur. Plon, 1989. Citado por Sodré, M. O social irradiado: violência urbana, neogrotesco e mídia, São Paulo: Cortez, 1992, p 15.

17 Levy, P. L'intelligence collective: pour une anthropologie du cyberspace, Paris: Découverte, 1994, p. 10.

18 Pela Internet, canção de Gilberto Gil, in Quanta,1996.

19 Armstrong, S Migration as a metaphor for change with respect to 116 legacy systems Computing Department, Faculty of Mathematics and Computing, Open University, Walton Hall.

20 Cf. Acselrad, M. Os sentidos da verdade: multiplicidade, paradoxo e linguagem, dissertação de mestrado, ECO/UFRJ, 1997.

21 Wolf, M. Teorias da comunicação. Lisboa: Editorial Presença, 1985, p. 83.

22 Cf. Bougnoux, D., Introdução às ciências da informação e da comunicação. Petrópolis: Vozes, 1994.

23 Nascimento, Aurélio Eduardo e Barbosa, José Paulo Trabalho: história e tendências. São Paulo: Ática, 1996 p.52. Citado por Del Nero, Henrique Schutzer Folha de S. Paulo, 30.maio.1995..

24 idem.

25 Carneiro Leão, E. "Os desafios da informatização" Aprendendo a pensar volume II. Petrópolis: Vozes, 1992 p.103.

26 Sodré, Muniz O monopólio da fala Petrópolis: Vozes, 1985 p.38. 